Shara Moseley

\title{
El poema en prosa moderno: consideraciones temáticas y formales
}

La crítica ha encontrado en el poema en prosa una configuración literaria de difícil clasificación, debido en parte a los problemas que plantea la propia definición del trabajo poético. Charles Baudelaire apuntaba ya el peligro inherente a la libertad absoluta que permite el poema en prosa $;^{1}$ e incluso Roman Jakobson comenta, no sin un dejo de ironía, que la frontera que separa lo poético de lo no poético es menos estable que aquella que divide a los territorios administrativos de la China. ${ }^{2}$ Por ello es pertinente definir el poema en prosa:

El poema en prosa desarrolla un asunto propio de la lírica y ofrece un conjunto armónico que proviene de la combinación de frases de ritmos variados que, sin embargo, generalmente se

1 «...car la fantaisie est d'autant plus dangereuse qu'elle est plus facile et plus ouverte; dangereuse comme la poésie en prose, comme le roman, elle ressemble á l'amour qu'inspire une prostituée et qui tombe bien vite dans la puérilité ou dans la bassesse; dangereuse comme toute liberté absolue" (CEuvres complètes II, p. 644). [ [“... pues la fantasía es tanto más peligrosa por ser más fácil y más abierta; peligrosa como la poesía en prosa, como la novela, se parece al amor que inspira una prostituta y que rápidamente se degrada en puerilidad o bajeza; peligrosa como toda libertad absoluta"].

2 Tomado de Questions de poétique, p. 114. 
subordinan a la estructuración semántica y sintáctica del discurso (Helena Beristáin, Diccionario de retórica y poética).

Aquí se habla de la estructuración discursiva del poema en prosa a partir de una combinación de armonía y ritmo; y resulta útil en la medida en que, aun cuando no sea completa, pone de manifiesto las dos cualidades del género, pese a que no lo defina completamente.

Debido a su amplitud y diversidad y a su resistencia a las definiciones que delimitan los géneros, el poema en prosa constituye un tema importante para entender la literatura posterior al Modernismo. A lo largo de este estudio, examinaré el poema en prosa y sus dos tendencias de desarrollo, representadas por Charles Baudelaire (1812-1867) y por Rubén Darío (1867-1916). Aun cuando no fueron los primeros en practicar este estilo, ambos poetas fueron quienes situaron al poema en prosa en el curso que seguiría a lo largo de la historia de la literatura; si este género implica, en términos generales, una ruptura con la versificación poética, Baudelaire y Darío le imprimirán un sello particular.

Habitante de la modernidad por antonomasia, Baudelaire escribió Spleen de Paris, petits poèmes en prose (1869), donde evitaba la rima y la métrica al tiempo que combinaba lo prosaico con lo poético. Por su parte, Rubén Darío, en Azul (1888-90), establecía ligas entre la idea y la musicalidad de las palabras. De este modo, el poema en prosa surge simultáneamente como expresión de la experiencia moderna y como una forma experimental en busca de una prosa más musical.

Realizaré en este trabajo un breve análisis del género, entendiéndolo en el contexto de la tradición literaria como una forma de continuidad, además de examinar sus desarrollos formales y temáticos. $\mathrm{Al}$ intentar determinar si el poema en prosa es una forma de continuidad o un sistema binario, encuentro que las nociones de continuidad y de ruptura no se oponen, 
sino que apuntan al papel de la experiencia y al arte de la reconstrucción textual en el ámbito moderno. En un segundo momento del análisis, me ocuparé de la combinación de poesía y de prosa, esto es, del lenguaje y de las formas que adoptará el poema en prosa. Por una parte, resulta claro que la recreación que hace el lector de la experiencia del artista constituye una de las condiciones del arte moderno; por la otra, que la atención a los aspectos formales produce un lenguaje poético más musical, afirmando la mezcla de géneros y alejándose de toda forma estructurada.

\section{El poema en prosa como continuidad}

¿Era acaso pretensión de la Modernidad romper con los preceptos de la escritura en tanto que representación; afirmar y negar, condensar y distorsionar el lenguaje, tal como lo sugieren algunos críticos? ¿Será cierto que encontramos a los protagonistas de "lo moderno" en el mero rechazo a toda forma anterior de escritura? En Convergencias, Octavio Paz explica que la poesía de "convergencia" no constituye una negación, sino la fusión de la vanguardia con la tradición (Convergencias, p. 5). Desde su punto de vista, "la poesía contemporánea [...] no rompe con la vanguardia: la continúa y al continuarla la transforma. No se trata pues de un movimiento, una escuela o siquiera una tendencia: es una exploración personal" (Convergencias, p. 139). La poesía de Rubén Darío resulta en este sentido convergente en su afán de transformar y exaltar la poesía a partir de la reelaboración formal de la literatura clásica; una suerte de "alpinismo poético" que el poeta describe como eco de una melodía familiar a la vez que como la sensación de extrañeza ante la existencia propia. De esta manera, a partir de la combinación de literaturas, y del deseo de trasladar el sentimiento a la canción, Darío unió la idea con la musicalidad de la palabra. 
Baudelaire, por el contrario, describía universos extraños, de odio hacia los hombres y a Dios. En su Aesthetic Experience and Literary Hermeneutics, Hans Robert Jauss encuentra que las descripciones de la ciudad y la modernidad del poeta francés representan una perspectiva moderna de la naturaleza, mientras que en su distorsión de la naturaleza evocan el pasado solamente para refutarlo, haciendo patente la capacidad humana de desintegrar esta nueva comprensión de la naturaleza en una estética del "juego" (p. 8). Jauss explica de qué manera la poesía de Baudelaire apela a lo visual. Así, la experiencia estética se proyectará en la poesía lírica moderna en tanto que creación contra la resistencia y opacidad de la naturaleza. Baudelaire elabora, pues, una perspectiva más afinada de lo nuevo, representación sorprendente a la que se aúna la experiencia del tiempo perdido que se torna recuperable (p. 11). Para Jauss, la formulación baudelaireana "ver es comprender" implicó una novedosa percepción de la literatura entendida como expresión que comunica una experiencia innovadora de los sentidos. Mientras Darío transformaba poesía y prosa en una nueva forma discursiva, Baudelaire ensayaba con ambos géneros la comunicación de las sensaciones del hombre en la modernidad.

De este modo, en el poema en prosa forma y contenido se unen de maneras distintas. Arte nuevo que se abre a la comprensión del lector, quien es invitado a reconstruir la obra. En relación con esto último, Jauss se vale del concepto construire de Paul Valéry, con el que explica al arte moderno como capaz de trascender la estética clásica.

Durante el proceso de escritura, señala Jauss siguiendo a Valéry, el artista pasa imperceptiblemente de la forma al contenido y del contenido a la forma (Aesthetic Experience..., pp. 51-55). Dicho de otro modo, en ocasiones la forma surge antes de la atribución de significado, o la idea de una forma significa tanto como la idea que busca formular: esto se debe a la interacción entre poïesis y aesthesis. 
En cuanto a la participación del lector, si bien inicialmente se trata de una contemplación que se abre al plaisir esthétique, poco después el lector se convierte en un "observador poético" que tiene necesidad de producir y reproducir (ibid., p. 61). De este modo en su teoría de la estética de la recepción Jauss incluye tanto el placer de la lectura como el de la reconstrucción textual. En esta última confluyen los conocimientos y las perspectivas personales del lector, el choque de distintos géneros, que distorsionan nuestra manera de ver las cosas, reformulando la reconstrucción del texto mismo, por lo que la novedad de la producción textual se produce a la vez desde la escritura y desde la lectura misma. Esto remite a la noción de convergencia de Paz y su planteamiento de acuerdo con el cual el acto de escribir constituye un deseo de redefinir el horizonte como un modo moderno de expresión artística:

Una poesía distinta y que, sin embargo, es la misma; la poesía de convergencia no es la negación sino la conversión de la vanguardia en tradición, es decir, un punto de partida. ¿Hacia dónde? Hacia el lugar de siempre: el presente inaccesible (Convergencias, p. 5).

Esta teoría rechaza la negación y considera al movimiento vanguardista como un viaje que eventualmente regresa a sus inicios en la tradición. Los ciclos literarios se suceden y finalizan en un presente inaccesible. Para Paz, ese lugar es aquel en donde el poeta intenta reconciliar su realidad con un ideal, y logra esto entendiendo el horizonte como un presente que surge un poco más allá de su comprensión. En el poema en prosa de Rubén Darío, "El fardo", el poeta "pinta" la línea azul del horizonte, de modo que al describirlo invita al lector a la contemplación: 
Allá lejos, en la línea como trazada con un lápiz azul que separa la aguas y los cielos, se iba hundiendo el sol, con sus polvos de oro y sus torbellinos de chispas purpuradas, como un gran disco de hierro candente (Obras completas I, p. 645).

Por el contrario, el poeta francés no presenta una imagen única que reproduzca su visión, sino que traza las imágenes conjuntamente con el lector. Además, como Edward Kaplan precisa, "Baudelaire se deshace de lo bello en tanto que línea divisoria del estatus de la obra de arte" (Baudelaire's Prose Poems, p. 57). Así, lo que inicialmente en el libro Fleurs $d u$ mal es una línea inamovible que el poeta habrá de encantar con espejos, ${ }^{3}$ en Spleen, tiembla en el horizonte como un velo azul. ${ }^{4}$ A pesar de sus diversas interpretaciones de lo que es el horizonte y su función, ambos poetas concuerdan con Paz en que el horizonte no es un sitio donde la tierra encuentra al cielo, sino aquel donde nuestros ojos perciben dicho encuentro.

\footnotetext{
${ }^{3}$ Del poema La beauté: "Je trône dans l'azur comme un sphinx incompris;/ J'unis un coeur de neige à la blancheur des cygnes;/Je hais le mouvement qui déplace les lignes,/ Et jamais je ne pleure et jamais je ne ris. [...] Car j'ai pour fasciner ces dociles amants, / De purs miroirs qui font toutes choses plus belles; I Mes yeux, mes larges yeux aux clartés étérnelles!" (versos 5-8, 12-14, Euvres complètes I, p. 21) [En el azur reino cual esfinge incomprendida;/ enlazo corazón de nieve y blancor de los cisnes;/ odio el movimiento que las líneas altera,/ y si nunca lloro es que nunca me río. [...] Para fascinar a tan dóciles amantes/ y que todo sea hermoso poseo límpidos espejos:/ ¡mis ojos, mis grandes ojos de brillo eterno (tr. de Jacinto Luis Guereña, Las flores del mal, pp. 52-53)].

4 Citando la segunda parte del poema en prosa Le confiteor de l'artiste: "Grand délice que celui de noyer son regard dans l'immensité du ciel et de la mer! Solitude, silence, incomparable chasteté de l'azur! Une petite voile frissonante à l'horizon, et qui par sa petitesse et son isolement imite mon irrémédiable existence, mélodie monotone de la houle, toutes ces choses pensant pour moi, ou je pense pour elles"(CEuvres complètes I, p. 278) [iQué gran deleite anegar la mirada en la inmensidad del cielo y del mar! ;Soledad, silencio, incomparable castidad del azul!, una pequeña vela se estremece en el horizonte, imitando en su pequeñez y aislamiento, mi irremediable existencia, monótona melodía del oleaje; todas estas cosas piensan por mí, o yo pienso por ellas..." (Pequeños poemas en prosa, pp. 52-53)].
} 
Tales meditaciones sobre el horizonte nos conducen a pensar que la modernidad de estos poetas se encuentra en nuestro entendimiento, dentro de nosotros, al decir de Paz ${ }^{5}$. Porque lo que ahora estimamos como moderno es el movimiento que se preguntaba por el porqué y el para qué de la poesía. Así, siguiendo a Paz, Baudelaire fue uno de los primeros en debatirse entre la subversión y la imitación, o la ruptura y la continuidad, y como lo hemos observado, ya sea subvirtiendo, imitando, continuando o rompiendo con el pasado, los poetas modernos tensaron sus arcos poéticos hacia el horizonte donde veían la convergencia entre pasado y el futuro.

El acto de escribir y el concepto de horizonte son importantes si pensamos en el poema en prosa como un encuentro en el presente de las tradiciones literarias. Tal como lo mencioné en relación con "El fardo" de Darío, el poeta dibuja una línea azul entre el cielo y la tierra que une la idea del azur de los simbolistas con el acto de escribir. Juan Valera identifica el término "azul” en su Carta prólogo como proveniente de Hugo, con las múltiples resonancias de "serenidad", "voz", "símbolo", "código", "color de un ideal", "infinito" y "etéreo" (p. 10). 6 Ante los ojos del poeta nicaragüense, "azul" se transforma en lugar para un pensamiento que sale del lenguaje prosaico y se revela a sí mismo; "azul” resulta entonces no sólo el horizonte en el sentido que Octavio Paz sugiere, sino también el acto de escribir el horizonte. En la colección Azul, vemos cómo Darío conjuga lo material con lo inmaterial, yuxtaponiendo lo real prosaico y lo onírico para llegar a la 'verdad' poética. El lenguaje de lo real, lo cierto y lo claro será entonces la poesía, y ya no la prosa. Pero Darío no construye en sus poemas en pro-

\footnotetext{
${ }^{5}$ Paz dice: "En mi peregrinación en busca de la modernidad me perdí y me encontré muchas veces. Volví a mi origen y descubrí que la modernidad no está afuera sino adentro de nosotros" (Convergencias, p. 21).

${ }^{6} \mathrm{Su}$ Carta prólogo puede encontrarse en ediciones de Azul como la de la Editorial Época de 1985.
} 
sa sistema binario alguno; las antedichas yuxtaposiciones son producto del pensamiento y no de la estructura.

Retornando a Paul Valéry y sus consideraciones sobre el lenguaje y la música como los dos grandes sucesos literarios de su tiempo, ${ }^{7}$ la literatura moderna intentaría reflejar las cualidades de la música, más que como musicalidad poética, como un estado sensorial. Para lograr una construcción musical sin rima o métrica, el lenguaje hubo de volcarse en sí mismo en tanto que estado mental repitiéndose, redirigiéndose y redefiniéndose en la irresolución.

La poesía trata de recuperar la sustancia acústica de las palabras. La música del poema modifica los conceptos de manera similar al modo como lo hace la respiración de un cantante. La respiración crea el ritmo y la musicalidad del poema en prosa, y su fusión con el lenguaje es una fusión entre el cantar y el pensar, más que entre contenido y forma. La música atravesará ambos, contenido y forma, modificándolos.

\section{El desarrollo temático del poema en prosa}

En este apartado identificaré el desarrollo temático de la prosa poética como una de las direcciones que este género difuso ha

\footnotetext{
7 "Les deux grands événements littéraires de mon temps, invisibles naturellement à la critique, sont: -le sentiment de plus en plus net des propriétés du langage, la tendance à agir sur le langage non plus par hazard et une fois mais par système, -le langage pressé, sommé, détaché même de tout; considéré dans toute son étendue, abstraitement ou dévéloppé par parties -par ses propiétés excitantes, par sa phonétique, par ses relations internes, etc. Et puis: la musique; et cet autre événement accompagne, complète, accélère le premier" (Cahiers II, p. 1160) [Los dos grandes acontecimientos literarios de mi tiempo, por supuesto invisibles para la crítica son: el sentimiento cada vez más claro de las propiedades del lenguaje, la tendencia a actuar sobre el lenguaje no por azar y una sola vez sino sistemáticamente, un lenguaje comprimido, decantado, separado incluso de todo, considerado en toda su extensión, de manera abstracta o aprovechado en partes - por sus propiedades excitantes, por su fonética, por sus relaciones internas, etc. Y por otra parte la música, este otro acontecimiento acompaña, completa y acelera el primero].
} 
seguido en su trayectoria histórica. Debido a la incapacidad del arte tradicional de representar la modernidad o de comprenderla, el arte moderno surgió como una forma de elaboración estética, a través de nuevas definiciones de los conceptos sobre la escritura, como la de poïesis de Paul Valéry. El poema en prosa desarrollará una nueva temática basada en las descripciones de la vida moderna y urbana.

El lugar de la modernidad difiere en los poemas en prosa de Rubén Darío y en los Baudelaire. La universalidad y perpetuidad de los trabajos de Darío contrastan con las descripciones de Baudelaire sobre la vida diaria, lo banal, e incluso lo feo. Y aun cuando ambos evitaban las reproducciones exactas de la naturaleza, demostraremos cómo el desarrollo temático resulta más fuerte en los trabajos del poeta francés, y le da al lector más posibilidades de reproducir su propia visión.

El principio valeriano del "ver puro" (ver más de lo que uno conoce), como aquel baudelaireano "ver es entender" 8 se opone al concepto de naturaleza. Baudelaire asevera que el conocimiento de la naturaleza a través de la mirada se puede tener solamente cuando se observa "cualquier esquina; cualquiera que ésta sea”. La esquina resulta arbitraria, pues corresponde a la perspectiva anti-naturalista de la indiferencia. Los poemas en prosa de Baudelaire constituyen un salto en la representación de la experiencia como una "pequeña esquina de la realidad" que el artista le ofrece al observador. Conforme el campo de visión se abre, el lector descubre que la "pequeña esquina

8 En su poema en prosa Chacun sa chimère [Cada uno su quimera], Baudelaire expone su deseo de mostrarle al lector la realidad y espera que la comprenda, aunque sabe que el observador puede quedar insensible ante ésta y no entenderla: "Et pendant quelques instants je m'obstinai à vouloir comprendre ce mystère; mais bientôt l'irrésistible Indifférence s'abattit sur moi, et j'en fus plus lourdement accablé qu'ils ne l'étaient eux-mêmes par leurs écrassantes Chimères" (CEuvres complètes I, p. 282) ["Y durante algunos instantes me obstiné en querer comprender este misterio; pero pronto cayó sobre mí la irresistible Indiferencia y quedé más agobiadamente postrado de lo que por su parte lo estaban aquéllos con sus abrumadoras Quimeras"]. 
de la realidad" no es una imagen última, sino que se abre, transparente, a otra cosa. Consideremos el ejemplo de L'étranger de Spleen de Paris y la imagen del hombre moderno que se siente extranjero en su propio país:

—Qui aimes-tu le mieux, homme énigmatique, dis? Ton père, ta mère, ta soeur ou ton frère?

-Je n'ai ni père, ni mère, ni soeur, ni frère.

-Tes amis?

-Vous vous servez là d'une parole dont le sens m'est resté jusqu'à ce jour inconnu.

-Ta patrie?

—J'ignore sous quelle latitude elle est située.

-La beauté?

-Je l'aimerais volontiers, déesse et immortelle.

-L'or?

-Je le hais comme vous haïssez Dieu.

-Eh! qu'aimes-tu donc, extraordinaire étranger?

_J'aime les nuages... les nuages qui passent... là-bas... là-bas... les merveilleux nuages! (Euvres complètes I, p. 275)

[-Dime, hombre enigmático, ¿a quién prefieres? ¿A tu padre, a tu madre, a tu hermana o a tu hermano?

- ¿A tus amigos?

-Empleais una palabra cuyo sentido me es hasta hoy desconocido.

—AA tu patria?

-Ignoro bajo qué latitud se encuentra.

— ¿A la belleza?

- Gustoso la amaría, diosa e inmortal.

- ¿Al oro?

—Lo odio como vosotros odiáis a Dios.

— ¿Qué es, entonces, lo que amas, extraordinario extranjero?

—Amo las nubes... las nubes que pasan... allá lejos... ¡las maravillosas nubes! (Pequeños poemas en prosa, p. 51)] 
En este poema en prosa, el poeta cuestiona los valores de familia, de la patria, de los amigos, de la belleza y del dinero; sin embargo, el extranjero no expresa lo que valora, sino que mira las nubes, y con esto interpretamos que el hombre se siente extranjero en la sociedad moderna. Baudelaire no le dice al lector qué entender; le ofrece en cambio el bosquejo de un sentimiento, le permite reconstruir libremente el texto de acuerdo al contexto histórico en el que se encuentra, y a lo que percibe en dicho contexto.

Kaplan llama a los poemas en prosa de Baudelaire "fábulas de la vida moderna", ya que son una forma de literatura de la experiencia diaria que carece del excesivo apetito por la forma (Baudelaire's Prose Poems, p. 2). De acuerdo con este crítico, las "fábulas" representan la creencia del poeta en que la vida verdadera constituye una mezcla de opuestos, confundidos en una ética que supera los dualismos y encuentra matices (ibid, p. 9). Baudelaire intentaba así demostrar cómo los horrores y el éxtasis de la vida existen simultáneamente en cada persona y que por tanto ese dualismo no constituye una representación válida de la verdadera vida. Kaplan cita la teoría de la amalgama, la multiplicidad de tonos, los matices del lenguaje y la disonancia, como figuras que el poeta francés esgrimió contra las ideas tradicionales de la literatura y el placer estético, en un intento de trazar una nueva dirección temática para la poesía y la prosa.

El papel que la vida moderna juega en los poemas en prosa de Rubén Darío resulta distinto del baudelaireano, pues en su caso estos poemas en prosa se dirigen a los problemas de la modernidad a partir de analogías con formas míticas y parnasianas. Consideremos la llegada del poeta a la corte en el siguiente fragmento de "El rey burgués": A diferencia de L'étranger de Baudelaire, donde el hombre se siente extranjero, aquí será el hombre o poeta el que será recibido como un extranjero: 
Un día le llevaron una rara especie de hombre ante su trono donde se hallaba rodeado de cortesanos, de retóricos y de maestros de equitación y de baile.

—¿Qué es esto? — preguntó.

- Señor, es un poeta.

El rey tenía cisnes en el estanque, canarios, gorriones, sinsontes en la pajarera; un poeta era algo nuevo y extraño.

-Dejadle aquí.

Y el poeta:

- Señor, no he comido.

Y el rey:

- Habla y comerás (Obras completas V, p. 625).

Darío se refiere a la malhadada situación del poeta moderno a fines del siglo XIX, describiéndolo como "una rara especie de hombre" que llega a la corte de un rey burgués como un ser extraño. Al ordenarle que se gane el pan como cualquier hombre, el burgués exhibe su menosprecio e ignorancia de la profunda universalidad y trascendencia de la poesía. En la obra de Darío es posible entonces hablar de los problemas de la modernidad fuera de su contexto histórico, donde el hombre puede ser representado por figuras míticas y aun por animales, para enfatizar los absurdos de la vida moderna.

Al evitar la imitación de la naturaleza, estos poetas pintaron lo que percibían personalmente. Mientras que Darío sacó al hombre del escenario moderno de todos los días, Baudelaire impugnó la realidad con lo cotidiano. Por ejemplo, sabemos que alrededor de 1846, el poeta francés habló de la importancia de la memoria, así como de sus reservas ante lo que consideraba el peligro del realismo fotográfico: "la memoria es el principal criterio del arte; el arte es una mnemotecnia de la belleza; ahora, la imitación exacta estropea la memoria" (Baudelaire As a Literary Critic, pp. 20-24). Y en su arremetida contra pintores del movimiento realista como Courbet, declaró que si continuaban pintando lo que todo el mundo veía, él los 
haría pintar su visión de la realidad: “¡No pintar más que lo que se ve!, entonces ustedes no pintarán más que lo que yo veo". ${ }^{9}$ A diferencia de sus predecesores, los poetas modernos no intentaban reproducir la naturaleza, sino producir un boceto de ella que pudiera revelar tanto las huellas de sus trabajos, como los contornos de sus sentimientos, y así permitirle al lector fabricar su propia visión.

\section{El desarrollo formal del poema en prosa}

Ya que el tono y el lenguaje tienen que ver tanto con la escritura como con la experiencia moderna, el poema en prosa establece una dirección formal cuyas pautas marcan constricciones o posibilidades para el artista. En este sentido, tal como lo muestra Roland Barthes, es necesario entender el lenguaje y la práctica de su escritura, para poder engañar al lenguaje mismo; ${ }^{10}$ pues de alguna manera, el lenguaje debe expresar la musicalidad de la forma para ser considerado poesía, y debe resultar claro y lógico para ser considerado prosa.

En la Historia de mis libros, Rubén Darío nos revela que las figuras formales empleadas en "El velo de la reina Mab" provienen del movimiento parnasiano francés:

Más que en ninguna de mis tentativas, en ésta perseguí el ritmo y la sonoridad verbales, la transposición musical, hasta entonces - es un hecho reconocido- desconocida en la prosa castellana... (Obras completas I, p. 200).

\footnotetext{
${ }^{9}$ Reproducimos aquí la cita completa: "L'art s'est retiré du pays. Grossièreté dans l'art...Philosophie des peintres belges, philosophie de notre ami Courbet, l'empoisonneur intéressé. Ne peindre que ce qu'on voit! Donc vous ne peindrez que ce que je vois" (Euvres complètes II, p. 932-33).

${ }^{10}$ Ver Leçon, Seuil, París, 1977, y Le plaisir du texte, Seuil, Paris, 1973.
} 
En otros poemas en prosa de la colección Azul, como "El rubî", "El palacio del sol" y "El pájaro azul" empleará, por ejemplo, el leitmotiv; mientras que en "Palomas blancas y garzas morenas"...

el tema es autobiográfico y el escenario, la tierra centroamericana en que me tocó nacer. Todo en él es verdadero, aunque dorado de ilusión juvenil. Es un eco fiel de mi adolescencia amorosa, del despertar de mis sentidos y de mi espíritu ante el enigma de la universal palpitación (Obras completas I, p. 200).

Darío se referirá a otros de sus poemas como ensayos de color y transposiciones pictóricas o de dibujo. El texto "A una estrella" constituye una combinación de géneros donde la idea y la musicalidad se alían en la palabra: "canto pasional, romanza, poema en prosa, en que la idea se une a la musicalidad de la palabra" (Obras completas I, p. 201). Ciertas maneras novedosas de emplear los adjetivos y ciertos modos sintácticos hasta entonces inéditos constituyeron importantes contribuciones al estilo moderno de la escritura en castellano. El poeta nicaragüense se reconoce influido por el realismo de Víctor Hugo (1802-1885) y de Gustave Flaubert (1821-1880), por el romanticismo de Théophile Gautier (1811-1872) y por Catulle Mendés (1841-1909), de la escuela Parnasiana.

Como en todos los poemas en prosa del libro Azul, la innovación no aparecerá tan sólo en el lenguaje, sino también en las formas que influyeron a Darío, esto es, el realismo, el romanticismo y el parnasianismo, de tal manera que vemos en "El velo de la reina Mab" un ejemplo de un vocabulario a la vez novedoso y parnasiano, poético y discursivo unido a una nueva forma sintáctica que permite tanto la prosa como la poesía. Comparemos el primero y último párrafos de este poema: 
La reina Mab, en su carro hecho de una sola perla, tirado por cuatro coleópteros de petos dorados y alas de pedrería, caminando sobre un rayo de sol, se coló por la ventana de una buhardilla donde estaban cuatro hombres flacos, barbudos e impertinentes, lamentándose como unos desdichados (Obras completas V, p. 652).

No es únicamente la repetición de las primeras palabras del primer párrafo al final del poema lo que le imprime ritmo, sino el uso de formas retóricas tales como aliteración y consonancia:

Entonces, la reina Mab, del fondo de su carro hecho de una sola perla, tomó un velo azul, casi impalpable, como formado de suspiros, o de miradas de ángeles rubios y pensativos. Y aquel velo era el velo de los sueños, de los dulces sueños, que hacen ver la vida del color de rosa (Obras completas V, p. 656).

El poeta describe cómo el hombre ve el mundo a través del arte, y aunque no emplee el verso, las formas retóricas le proporcionan musicalidad a su prosa.

Por otra parte, sabemos que para Baudelaire el poema se desarrolla sobre una palabra profunda y misteriosa, mientras que la prosa implica deficiencias colosales. ${ }^{11}$ Así, para él, la sonoridad y el ritmo pueden imitar los sentimientos de la melancolía traspuestos en frases que estimamos musicales, como se ve en "Un hémisphere dans une chevelure" ["Un hemisferio en una cabellera"]:

11 “... Poème singulier entre tous. Il roule sur un mot mystérieux et profond... Dans le moulage de la prose appliqué à la poésie, il y a nécessairement une affreuse imperfection” (Euvres complètes II, p. 344) [“...Poema singular entre todos. Funciona a partir de una palabra misteriosa y profunda. En la adaptación de la prosa a la poesía hay necesariamente una terrible imperfección”]. 
Laisse-moi respirer longtemps, l'odeur de tes cheveux, y plonger tout mon visage, comme un homme altéré dans l'eau d'une source, et les agiter avec ma main comme un mouchoir odorant, pour secouer des souvenirs dans l'air (CEuvres complètes I, p. 300).

[Déjame respirar mucho tiempo, mucho tiempo, el olor de tus cabellos, hundir en ellos mi rostro entero, como un hombre sediento en el agua del manantial, y agitarlos con mi mano como un pañuelo oloroso, para sacudir los recuerdos al aire (Pequeños poemas en prosa, p. 76)].

En este pasaje, Baudelaire nos hace sentir los recuerdos como una melodía; recuerdos que cobran su propia sustancia casi hasta poder sacudirse en el aire. Este poeta que describe la experiencia de recordar con tanta sutileza admite, por otro lado, que no conoce un método sencillo para definir lo que es musical, y añade que sólo debemos escuchar las estrofas de la poesía en nuestra memoria y entonces decidir qué es lo que hace quejumbroso a Lamartine, magnífico a Hugo y sutil aunque comprensible a Gautier.

El lenguaje es una parte esencial de la musicalidad del poema en prosa. De acuerdo con Valéry, la escritura es un proceso de deformación y mutilación del pensamiento y no del lenguaje. Difiere en esto de Octavio Paz y aun de Stéphane Mallarmé, quien decía que no escribía poesía con pensamientos, sino con palabras. Ahora bien, quizás los planteamientos de los tres poetas no resulten tan divergentes si pensamos en la explicación de Valéry sobre el pensamiento como reverso de la escritura. No se trata de plantear que el pensamiento precede a las palabras, sino de entender la escritura como un proceso pensado que se vuelve sobre sí mismo, en el que el artista pasa casi sin distinción de la forma al contenido y del contenido a la forma.

El desarrollo formal del poema en prosa revela los procesos escriturales de la literatura moderna. Los ejemplos de Rubén 
Darío y de Charles Baudelaire muestran innovaciones tanto en el nivel temático como en el formal. Para el poeta nicaragüense, lo poético y lo discursivo presentan un desarrollo más formal en las palabras y en cuanto a las formas sintácticas que hacen del poema en prosa un texto musical. Por su parte, el poeta francés desarrolla primero el tema que comunica sus sensaciones eligiendo las palabras no solamente por su ritmo y sonoridad, sino por los sentimientos que evocan.

\section{Conclusión}

A la luz de las recientes propuestas de una literatura libre de género o de canon, el debate en torno a la condición genérica del poema en prosa continúa. Por nuestra parte, preferiríamos considerar al poema en prosa como un género verdadero, aunque sólo fuera para garantizar su entrada al ámbito de la enseñanza de la literatura en el aula. Después de todo, ¿un género no es, como han sugerido Bajtín y Todorov, un instrumento para los estudiantes de literatura, al igual que un diccionario es una herramienta para el estudioso del lenguaje? Además, así como todo arte precede a su tiempo, el poema en prosa representa una transformación de la propia literatura al adelantarse a los planteamientos teóricos en más de medio siglo; la crítica literaria ha tardado en seguirle el paso. Mucho antes de que los críticos comenzaran a considerar el interés de estudiar textos que no encajaban bien dentro de las categorías canónicas, los movimientos de vanguardia de los '20 y luego los de los '60 mostraron dos tendencias: por un lado, un desarrollo temático que seguía al poema en prosa de Charles Baudelaire al abordar la vida moderna y, por el otro, la búsqueda de nuevas formas, tal como las anunciara el poema en prosa de Rubén Darío.

Traducción de Cristina Mújica 


\section{Bibliografía}

Beristáin, Helena, Diccionario de retórica y poética (8a edición), Porrúa, México, 2000.

Baudelaire, Charles. Euvres complètes (2 vols.), Gallimard, París, 1975.

—Las flores del mal (trad. de Jacinto Luis Guereña), Ed. Visor, Madrid, 1996.

- Pequeños poemas en prosa. Los paraísos artificiales (ed. y traducción de José Antonio Millán Alba), Cátedra, Madrid, 2000.

Darío, Rubén. Azul, Editorial Época, México, 1985.

- Obras completas (5 vols.), Afrodisio Aguado, Madrid, 1950.

Hyslop, Lois Boe y Francis E. Hyslop Jr. (editores y traductores), Baudelaire As a Literary Critic, Pennsylvania State University Presses, University Park, 1964.

Jauss, Hans Robert, Aesthetic Experience and Literary Hermeneutics, (trad. al inglés de Michael Shaw), Minnesota University Press, Minneapolis, 1982.

Kaplan, Edward D. Baudelaire's Prose Poems. The Esthetic, the Ethical and the Religious in The Parisian Prowler, Universidad de Georgia, Athens, 1990.

Paz, Octavio, Convergencias, Seix Barral, Barcelona, 1991. 